Article

\title{
Empirical Study on Structural Safety Diagnosis of Large-Scale Civil Infrastructure Using Laser Scanning and BIM
}

\author{
Namhyuk Ham and Sang-Hyo Lee * \\ Division of Architecture and Civil Engineering, Kangwon National University, 346, Jungang-ro, \\ Samcheok-si 25913, Gangwon-do, Korea; aaschool81@gmail.com \\ * Correspondence: leesh0903@kangwon.ac.kr; Tel.: +82-33-570-6527
}

Received: 12 September 2018; Accepted: 31 October 2018; Published: 2 November 2018

check for updates

\begin{abstract}
Existing structural safety diagnosis methods are time-consuming due to personnel-oriented measurement methods and have a limitation that it is difficult to obtain consistent research results. In order to overcome these limitations, this study proposes a structural safety diagnosis method using laser scanning and BIM. In spite of the various studies related to laser scanning and BIM, it is difficult to find a study that verifies the effect of shortening the service period and cost reduction in terms of project management. Therefore, in this study, case analysis of structural safety diagnosis of large-scale civil infrastructure was conducted. In the structural safety diagnosis, the laser scanning data and the BIM model were compared and analyzed to determine the degree of deformation of pipe rack (e.g., truss, column). Laser scanning data reflects the deformation state of large-scale civil infrastructure. On the other hand, the BIM model was constructed by reflecting the state before the transformation with reference to the laser scanning data. Finally, proposed method of structural safety diagnosis saved four months. In terms of manpower saving, 125 man-month was saved. The research findings can provide a quantitative basis for the introduction of laser scanning and BIM technology in the structural safety diagnosis of aging large-scale civil infrastructures. However, the limitations of this study have not been analyzed economically by considering the investment cost (e.g., hardware, software, training, etc.) of laser scanning and BIM technology and the cost saving effect of technology introduction.
\end{abstract}

Keywords: large-scale civil infrastructure; structural safety diagnosis; laser scanning; BIM; empirical study

\section{Introduction}

Facility management is important for AEC/FM organizations to maintain a sustainable business [1,2]. In particular, the safety inspection of infrastructure, such as aging bridges [3], highways and rail [4], traffic facilities (e.g., tunnel) [5], and pipe racks [6,7], needs to be urgently dealt with in light of the possible economic damage owing to sudden safety accidents and operational interruptions. However, few case studies have been conducted on the safety inspection of large-scale civil infrastructure. The Facility Management System of the Korea Infrastructure Safety Corporation manages information concerning 90,989 facilities across the country. The infrastructure for most of these facilities was constructed in the 1970s and 1980s [8]. The increase in the number of aging facilities increases management costs, and may lead to serious safety problems if accurate safety diagnosis and maintenance are not performed [9]. Therefore, a system capable of inspecting and managing aging facilities in advance is required for their efficient maintenance.

A facility safety inspection refers to the process where experts equipped with experience and the relevant technologies examine factors affecting safety in facilities [4]. Precision structural safety 
diagnosis refers to the process whereby the physical and functional defects of a facility are found, and methods to repair and reinforce them are suggested by investigating, measuring, and assessing structural safety, as well as the cause of such defects to take prompt and appropriate measures [10]. Precision structural safety diagnosis secures data required to determine the status and state of safety of a facility through precise observations, measurements using testing equipment, and tests to identify defects that cannot easily be detected otherwise by safety inspection. Status assessment refers to the behavior whereby the exterior of a facility is investigated, and the status of the facility, including the degrees of defects in it, is assessed. Safety assessment can be conducted using various methods, such as the non-destructive loading test, ground investigation, and exploration, measurement, and analysis according to the type of facility and its structural characteristics [10]. Currently, operational facility safety diagnosis are carried out either by time-consuming site inspections or semi-automatically by visually analyzing imagery and video data [4].

In general, facilities requiring precise structural safety diagnosis are often very large, such as tunnels [5,11] and bridges [3]. In addition, there are many complicated cases such as the production line inside the plant (e.g., nuclear power plant pipeline) [6], and the infrastructure (e.g., pipe rack) that supplies the production resources [7]. The prevalent method of safety inspection derives risk factors through comprehensive visual inspection, operational status check, and diagnostic equipment based on checklists for each facility and type of infrastructure. This process of safety inspection requires the long-term input of numerous personnel $[4,12]$. As this method involves the inspection of large-scale civil infrastructure through separate measurements, it is challenging to obtain consistent results of inspection, because the outcomes of safety diagnosis can differ depending on the capabilities of the engineers. Furthermore, safety diagnosis is performed while the facility is in operation. Therefore, the diagnosis itself entails high risk [13]. Although the data generated in each step of safety diagnosis are in varied formats and large in number, they lack consistency and, thus, are not easily manageable. In particular, in case of aging facilities, field surveys, status assessments, and safety assessments are challenging because the design information is not properly managed, and it is difficult to find the history of the modification of the facility. Moreover, sufficient information concerning the status of a facility that can be used for safety diagnosis is not available.

Laser scanning can be considered to overcome the limitations of existing structural safety diagnosis method [14]. Laser scanning technology offers the following benefits compared with the typical contact-type sensors used in the architecture, engineering, and construction (AEC) industries [15]: (1) It can perform high-speed scanning of large facilities, and can measure the surface profile. (2) It provides millimeter-unit accuracy and spatial resolution through point cloud data. (3) It can theoretically provide long-distance measurements of up to $6000 \mathrm{~m} \mathrm{[16].} \mathrm{Owing} \mathrm{to} \mathrm{these} \mathrm{characteristics,} \mathrm{laser} \mathrm{scanning}$ technology has been used in reverse engineering [17,18], monitoring deflection and deformation [13], monitoring the progress of construction [11,19], and topographical surveys [20]. Along with laser scanning, building information modeling (BIM) has been widely used in the construction industry to help construct, store, and manage information created during the lifecycle of a facility [21]. For instance, participants of the construction project of the AEC/facility management (FM) area can obtain the information needed for their tasks using BIM [15]. Some recent studies have combined the benefits of these two technologies [22,23]. Therefore, in this study, we will examine the effect of structural safety diagnosis of large-scale civil infrastructure using laser scanning and BIM.

\section{Literature Review}

\subsection{Laser Scanning Technology}

Three-dimensional laser scanning technology collectively refers to technologies capable of acquiring and adjusting 3D point clouds, such as light detection and ranging (LiDAR) [9]. Compared with currently used technology, laser scanning directly collects 3D data on facilities at high precision and resolution $[24,25]$. Owing to these benefits, researchers in many fields have studied it. 
Some studies on the reverse design that creates 3D models from laser scanning data are as follows: Nahangi et al. [26] researched the removal of error from laser scanning data and their clustering. Son et al. [27] researched the semantic creation of 3D models required in construction from laser scanning data. Gimemez et al. [28] investigated technology related to creating 3D building models from 2D scan data. Bosche et al. [29] proposed a method to monitor facilities by converting 3D scanning data for the MEP pipe shape into BIM data. Reeder et al. [30] focused on a method to model data required for engineering through 3D image scanning of highways. Murphy et al. [31] researched assessment standards for 3D image adjustment, and Bhatla et al. [32] conducted research on methods of precision assessment for as-built 3D modeling.

From the perspective of the quality assessment (QA) of facilities, some studies on the application of laser scanning technology are as follows: Bosche [33] proposed an automated technique to recognize 3D CAD objects from laser scanning data for the visual inspection of facility elements. Shih and Wang [34] proposed a system to measure the quality of construction of completed structures (e.g., walls). Akinci et al. [35] proposed a general framework to inspect the quality of facilities by comparing as-built models acquired from laser scanning data using CAD models. Han et al. [36] proposed an automated technique to extract the cross-section of a tunnel from laser scanning data for quality management. Gordon and Lichti [37] and Park et al. [13] acquired the results of measurements of facility deformation from laser scanning data.

Some studies on improving the accuracy of laser scanning technology are as follows: Teza et al. [38] proposed a damage detection technology based on the calculation of the average and Gaussian curvatures of concrete surfaces. Tang et al. [39] investigated the detection of the surface flatness detects of facilities using various damage detection algorithms and a 3D laser scanner. Olsen et al. [25] proposed a technique to quantify the lost volume of reinforce concrete structures, and Liu et al. [40] proposed an in-situ distance-and-gradient-based volume loss estimation technique for concrete bridges.

In addition, Golparvar-Fard et al. [41] conducted a study on the accuracy evaluation of image-based modeling and laser scanning. Brilakis et al. [42] conducted a study to automatically generate BIM models based on hybrid video and laser scanning data. Zeibak-Shini et al. [43] conducted a study to estimate the damage site of structures using laser scanning and as-built BIM. Despite the various studies mentioned above, it is difficult to find any research on project duration and labor saving when laser scanning is applied for project management.

\subsection{Role of BIM in Facility Management}

In general, BIM is defined as a model that contains the lifecycle information of a construction project or its process for construction [44]. In facility safety management, the success of the application of BIM depends on how efficiently the information generated at the design and construction stages is handled up to the operation stage [45-47]. BIM significantly influences the FM stage in that owners and facility managers require computerized information concerning facilities that can improve the existing method of safety diagnosis [48]. Therefore, BIM requires information concerning facilities that is consistent over time [49].

However, information concerning facilities is scattered in documented construction specifications, warranties, and operation and maintenance manuals [50]. Safety problems with facilities may occur in unexpected places [51]. The information used for the safety diagnosis of facilities consists of as-built documentation created by the general contractor and sub-contractors who participated in the construction. In case of the latest construction projects to which BIM was applied, the completion status was reflected in the as-built drawings or models, which could be utilized to operate the facilities. In the case of aging facilities, however, as-built drawings are lost or are different from the given scenario because of long-term operation in most cases. Therefore, the role of BIM in facility management is to provide comparative data on the status information of facilities collected through laser scanning to determine the degree of transformation of facilities [14]. 
As shown above, Laser scanning and BIM have a number of advantages that can improve the structural safety diagnosis of large-scale civil infrastructure. Using a case study where laser scanning and BIM were applied to the structural safety diagnosis of a large-scale civil infrastructure, this study investigates (1) the benefits of laser scanning and BIM in structural safety diagnosis of aging facilities, and (2) the investigation method of the deformation state of large-scale civil infrastructure by comparing laser scanning data with BIM model.

\section{Structural Safety Inspection of Civil Infrastructure Using Laser Scanning and BIM}

\section{Generation of Safety Diagnostic Information for Large-Scale Civil Infrastructure}

For aging civil infrastructure, the completed documents generally do not match its status at any given time owing to long-term operation. Safety diagnosis must be based on accurate information concerning the state of civil infrastructure. The proposed information generation process based on laser scanning and BIM for the safety diagnosis of civil infrastructure is shown in Figure 1. This structural safety diagnosis was established through an expert interview with Dongyang Structural Engineers Group, a company carrying out the case project. The steps of the process are described as follows.

(1) The as-built drawing contains the completion information of a facility [17]. In the case of civil infrastructure, however, the drawings can be lost during operation, or they do not match the status at the given time in many cases. Therefore, it is difficult to use this information for safety diagnosis.

(2) The as-built BIM data refer to the 3D model built based on the completed drawings of a facility, and contain information concerning the shape of the facility. As-built BIM data are generated based on as-built drawings. However, if there is no as-built drawing, the as-built BIM data should be prepared before the transformation by referring to the laser scanning data [15].

(3) Three-dimensional laser scanning refers to scanning a facility in operation in three dimensions using a 3D laser scanner. When the given facility is large or complex, laser scanning can acquire accurate information concerning its status by designating scanning points at various positions [5].

(4) Three-dimensional laser scanning data can be generated by integrating data scanned from multiple positions [23]. The data contain accurate information concerning the surface of the facility in a point cloud data format. From the data, accurate information concerning shape required for the safety diagnosis of the facility can be obtained. In other words, laser scanning data contain status information, which reflect construction errors and displacement, that is unknown in the as-built BIM data.

(5) The accurate as-built BIM data must be modeled based on laser scanning data [33]. Safety diagnosis must be performed consistently instead of once. The BIM model should be a criterion for determining the degree of deformation of the laser scanning data that accurately reflects the deformation state.

(6) If laser scanning is repeated in the future for the safety diagnosis of a facility, the modifications in it can be consistently monitored by directly comparing laser scanning data generated in the previous safety diagnosis and the as-built BIM data [12].

(7) Field survey data relating to the external conditions of facilities are obtained by investigating the design documents and related materials, the damage status of the components of the facility, their deformation status, and the application status of the load. The data include the tilt, displacement, crack, and surface damage information of the components [10].

(8) The laser scanning data and the BIM model should be integrated on the basis of specific coordinates to more accurately analyze the results of the external condition of the large-scale civil infrastructure [18,26]. The integrated 3D model is used to determine the degree of displacement through cross-sectional analysis. 
(9) The field survey data concerning the internal conditions of a facility include information concerning the cross-section of constituents of the facility. The data include information concerning the cross-sectional status and performance of the components, such as the fire-resistant covering of steel components, film thickness, bolt-tightening force, neutralization information for reinforced concrete components, and compressive strength. Such information is directly surveyed from the field [10].

(10) BIM data develops by reflecting the field survey data in terms of the internal conditions (e.g., material, size, etc.) of facilities [29].

(11) The BIM model reflecting the internal characteristics of the facility can be utilized as a structural analysis model for accurate structural safety diagnosis [45]. Therefore, it is possible to easily extract a model for accurate structural analysis using BIM authoring tool (e.g., revit).

(12) Data for accurate structural analysis can be generated using this model. Such data are used to repair and reinforce facilities [37].

(13) Facilities are subject to deformation over time owing to the aging of the constituent materials or the effect of external forces. Therefore, the information generation process for facilities can be repeatedly used according to the period of safety inspection of the corresponding facility [13]. Through this, it is possible to consistently manage safety and secure the data.

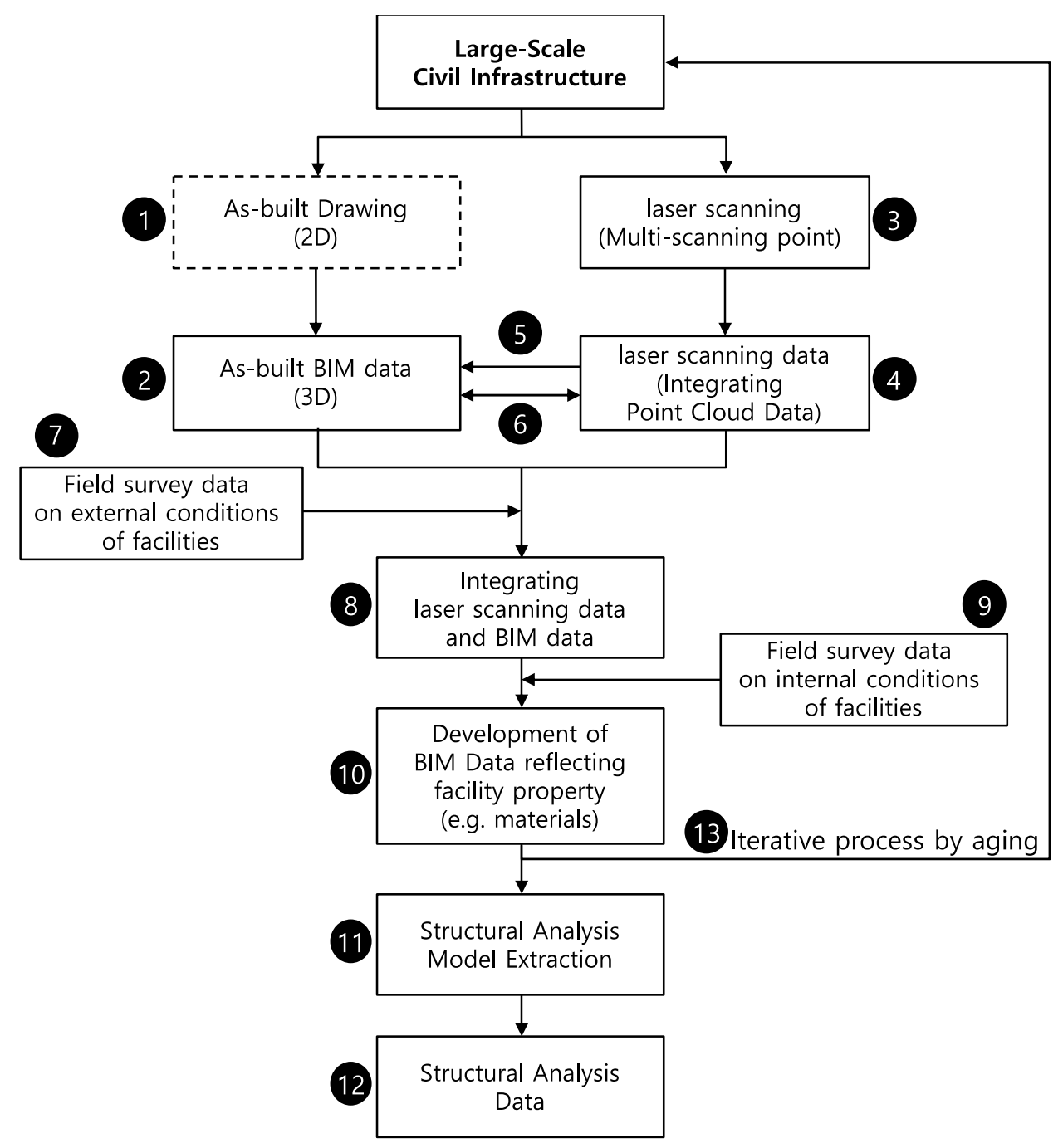

Figure 1. Laser scanning and BIM-based information generation process for civil infrastructure structural safety diagnosis. 
As a result of the expert interview, a large amount of manpower is invested in the long-term for the initial field investigation, data preparation and data collection for structural safety evaluation in the structural safety diagnosis of large facilities. We expect to save not only time but also manpower by replacing this labor-intensive work with laser scanning.

\section{Case Study}

\subsection{Project Description}

Ulsan plant of the $\mathrm{H}$ company was used for the case study of this research. The case project is the largest single factory in the world with an area of 5,000,000 square meters. The Ulsan plant consists of five finished car factories, engine and transmission plant, and road driving/crash test site that can be independently produced. It is the largest single factory in the world, producing an average of 5400 vehicles a day. It is a large-scale civil infrastructure that can cause enormous losses economically if production safety is interrupted due to facility safety problems. The factory was built from 1968 to 1975. Thus, the factory required structural safety diagnosis of the facilities owing to aging. Especially, the scope of the case project is a structural safety diagnosis for pipe racks. The pipe racks of the factory represented pipes and racks used for raw material transport inside the factory. Figure 2 shows the layout of a case study project for a pipe rack. Yellow, green, pink, and red indicate the path of the main pipe rack.

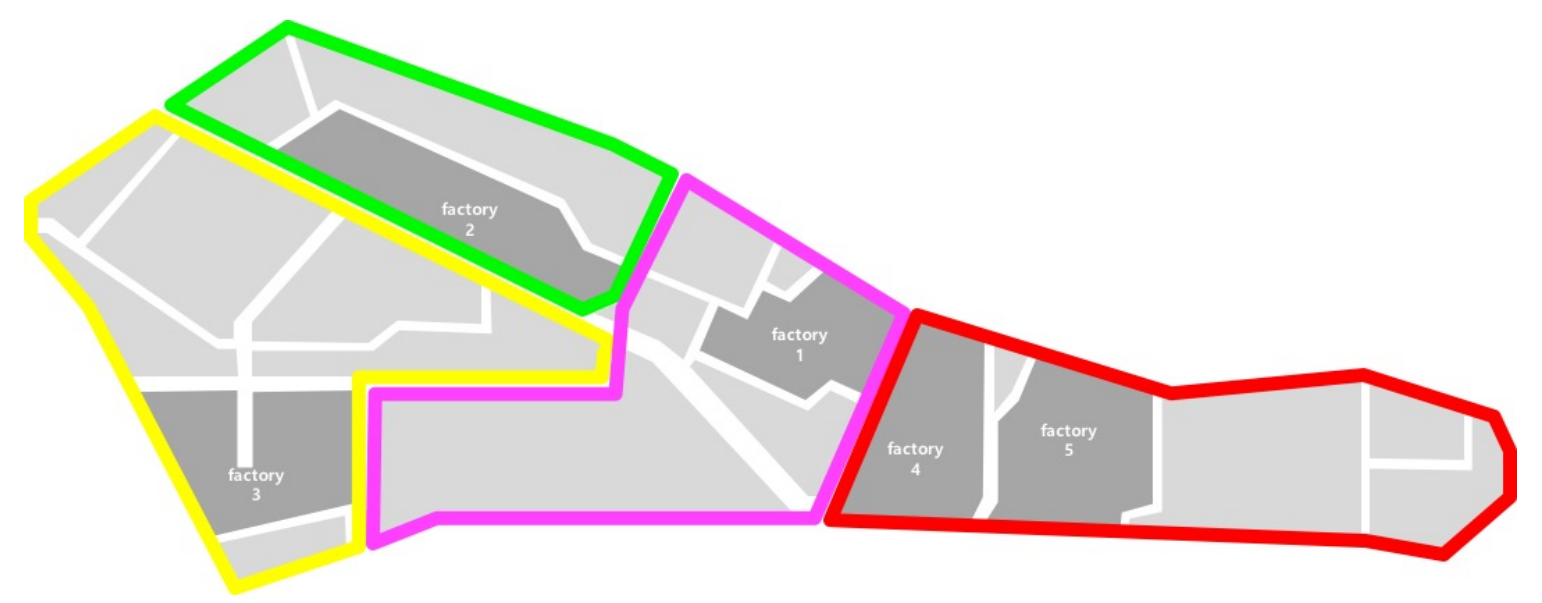

Figure 2. Layout of a case study project for pipe rack.

As the design documents created by the company that previously performed the structural safety diagnosis had been different from the status of the plant at the time, the safety diagnosis of the facilities could not be properly performed. Moreover, the facilities were large, the prevalent personnel-oriented method of safety diagnosis was not economically efficient. Therefore, the authors performed a safety diagnosis of the aging pipe racks in the factory using laser scanning and BIM technologies. Dongyang Structural Engineers Group, which executed this project, is a structural engineering design office that has examined the status of construction in factories, performed structural safety diagnosis and maintenance, reverse engineering, and managed the quality of construction of irregular buildings using BIM and laser scanning.

\subsection{Laser Scanning- and BIM-Based Civil Infrastructure Safety Inspection}

\subsubsection{Equipment}

The 3D laser scanner used in this case study was the TX8 model supplied by Trimble, and its specifications are shown in Table 1. TX8 is a high-performance 3D laser scanner used to acquire precision data. The representative characteristics of this model are that it can perform ultra-high-speed 
scanning using Trimble's lightning technology and acquire data in a stable manner regardless of the reflectivity of the target object. The speed of basic point cloud acquisition was 1,000,000 points/s, indicating that the model was suitable to scan large-scale facilities.

Table 1. Specifications of 3D laser scanner (TX8 supplied by Trimble).

\begin{tabular}{cc}
\hline Category & Specification \\
\hline Scan speed & $1,000,000 \mathrm{pts} / \mathrm{s}$ \\
Scan range & Horizontal $360^{\circ} / \mathrm{vertical} 317^{\circ}$ \\
Scan distance & $0.6-340 \mathrm{~m}$ \\
Scan time & $2-14 \mathrm{~min}$ \\
IP rating & $\mathrm{IP} 54$ \\
Accuracy & $1 \mathrm{~mm}(2-80 \mathrm{~m})$ \\
Laser class & $\mathrm{Class} 1$ \\
RGB & External camera \\
Tilt sensor & $\mathrm{O}\left(0.5^{\prime \prime}\right)$ \\
Operating temperature & $0-40^{\circ} \mathrm{C}$ \\
\hline
\end{tabular}

Furthermore, the scanner supported an intuitive and simple touchscreen interface as shown in Figure 3. All functions of the scanner could be controlled via the touchscreen. Constantly accurate data could be acquired regardless of weather conditions. The scanner could be used in combination with images from high-resolution cameras and point cloud data. The applications of this 3D laser scanner are wide-ranging, including surveying, industrial facilities, civil infrastructure, mines and quarries, deformation monitoring, quality control, urban environment, building as built, building MEP, BIM, and VDC, tank calibration/inspection, preservation and restoration, and public safety and forensics [52].

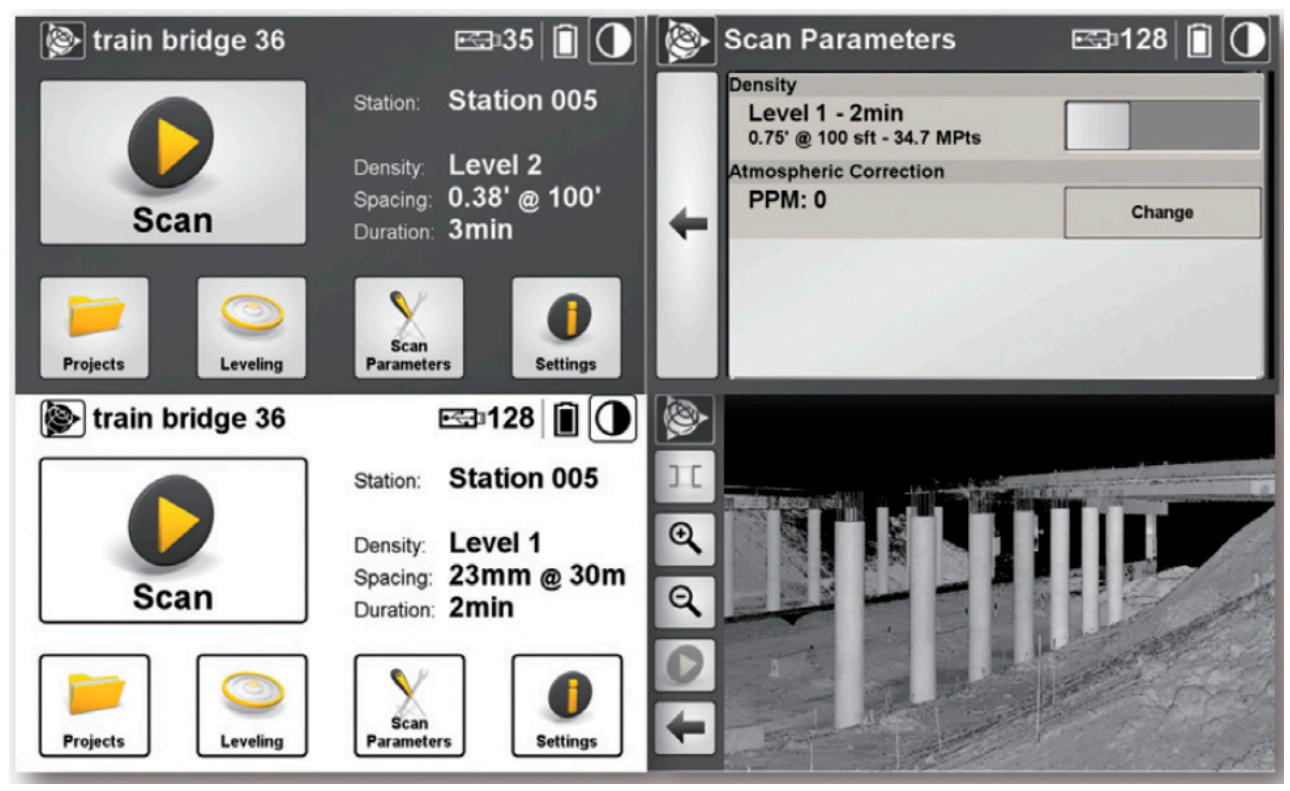

Figure 3. Interface of TX8.

When the as-built BIM data were generated using point cloud data, multiple software programs were used. Autodesk's ReCap, Revit, Plant3D, and Civil3D; Trimble's Realworks and Tekla; Intergragh's PDS and Smart Plant3D, Leica's Cyclone and CloudWorkx; and Faro's PointSense Plant provide solutions for the management, adjustment, analysis, simulation, automatic modeling, and 3D modeling of point cloud data so that the status of facilities can be easily modeled [53]. In this study, the as-built BIM data were generated through Revit using point cloud data because connection to 
model generation for structural analysis and the structural analysis task, which are follow-up tasks, was considered as the safety diagnosis of the status of the facilities was the final objective.

\subsubsection{Process}

\section{Preliminary Field Survey}

A preliminary field survey of the project revealed problems of constituent deformation, such as deflection of structural beam, height increase due to pipeline expansion, subsidence and junction defects as shown in Figure 4. Accordingly, inspections of aging facilities, enhanced facilities, and external deformation were required. As a result of the interview with the project manager of the structural engineering company, the prevalent personnel-oriented method of safety diagnosis was applied, 20 personnel for three months would have been needed only for field measurements. It was also found that 25 personnel for three months would have been needed for model creation, structural analysis, and data summary. A number of restrictions also applied, including a limited survey period, the absence of past data, complex structural systems, and risks of high-place work. Therefore, laser scanning and BIM were used for the safety diagnosis of the project.
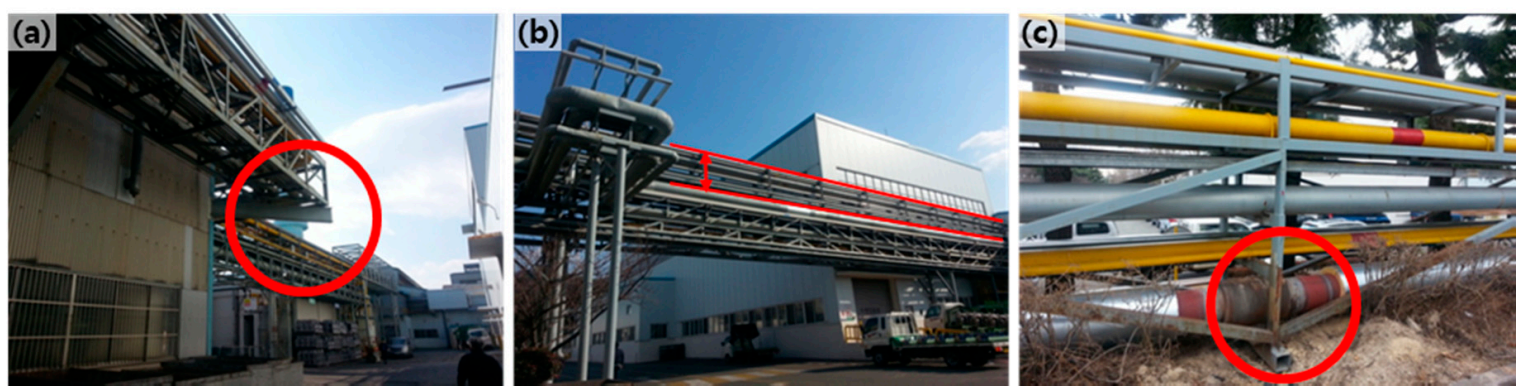

Figure 4. The results of the preliminary field survey: (a) deflection of structural beam, (b) height increase due to pipeline expansion, and (c) subsidence and junction defects.

Preliminary Survey of the Location and Status of Target Building

Prior to performing 3D laser scanning, a preliminary survey on the location and status of the target building was conducted as shown in Figure 5 to examine the performance of the 3D laser scanner. As the scale of the case project was large, it was impossible to generate the integrated point cloud data for all facilities at a time. To improve the accuracy of the safety diagnosis, the facilities were divided and integrated point cloud data were obtained.

In order to improve the efficiency of structural safety diagnosis, the structural safety diagnosis scope of case project was set around the long span where deformation is expected. As shown in Table 2, the total length of the area surveyed by laser scanning is close to $1 \mathrm{~km}(959.2 \mathrm{~m})$ in this case project.

Therefore, as shown in Figure $6 \mathrm{a}-\mathrm{c}$, complicated areas where the pipe rack path changes or facilities are integrated are excluded from the structural safety diagnosis. Figure $6 a-c$ shows an examples for a site to be surveyed. In order to minimize the manpower for a certain period of time, the scope of the survey was set up using laser scanning around the main long span area. 

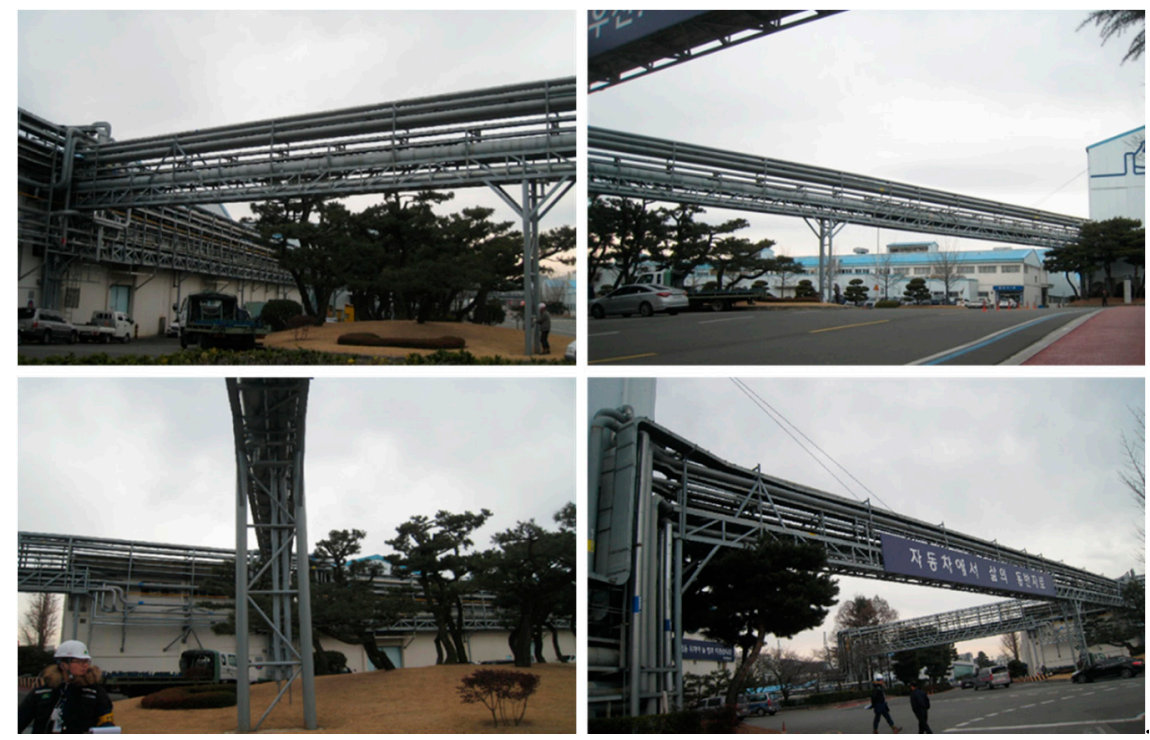

Figure 5. Preliminary survey of the location and status of pipe racks.

Table 2. Total structural safety diagnosis service scope of case project using laser scanning.

\begin{tabular}{cc}
\hline No. of Survey Sections & $\begin{array}{c}\text { Scope of Structural Safety Diagnosis Using Laser } \\
\text { Scanning: Straight Length } \mathbf{( m m})\end{array}$ \\
\hline No. 1 & 50,000 \\
No. 2 & 133,200 \\
No. 3 & 79,180 \\
No. 4 & 96,240 \\
No. 5 & 57,300 \\
No. 6 & 143,130 \\
No. 7 & 144,700 \\
No. 8 & 26,820 \\
No. 9 & 61,130 \\
No. 10 & 55,780 \\
No. 11 & 38,240 \\
No. 12 & 39,200 \\
No. 13 & 34,280 \\
Total & 959,200 \\
\hline
\end{tabular}

\section{Laser Scanning}

Figure 7 shows the results of integrating laser scanning points for the target facilities and the point cloud data scanned at each point. To acquire the point cloud data for the target facilities, scanning was performed at five points, and it took two to three minutes per point. The point cloud data acquired from each scanning point were integrated into a file using Trimble's Realworks. In the case project, pipe racks are not only large in size but also vary in location. The global positioning system (GPS) coordinate system was used to manage laser scanning data for large-scale civil infrastructure. According to the results of interviews with structural experts, the coordinate system can use relative coordinates instead of absolute coordinates depending on the type, size, and service range of the project. 


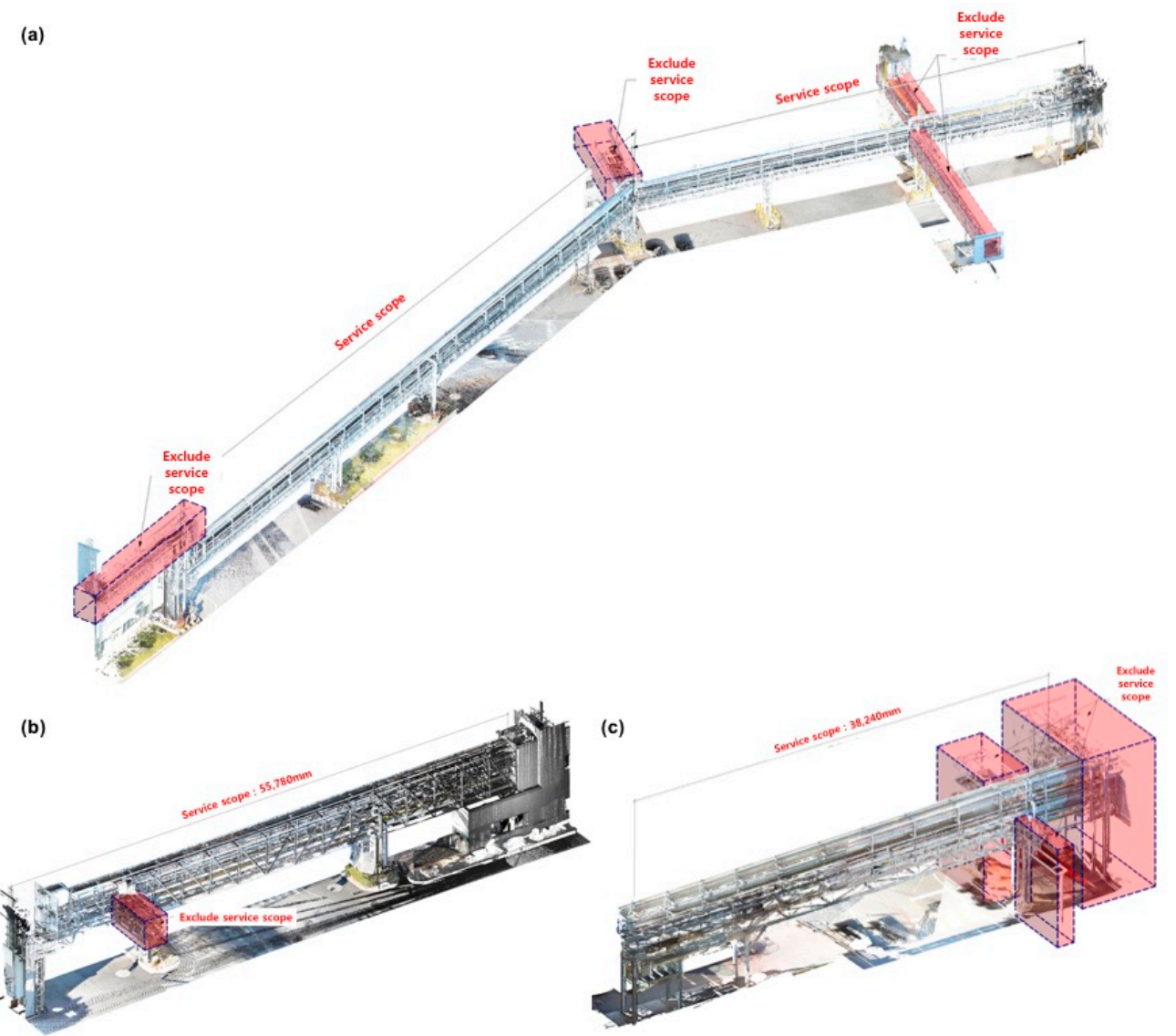

Figure 6. Scope of structural safety diagnosis using laser scanning: (a) case 1 for Service Scope, (b) case 2 for Service Scope, and (c) case 3 for Service Scope.

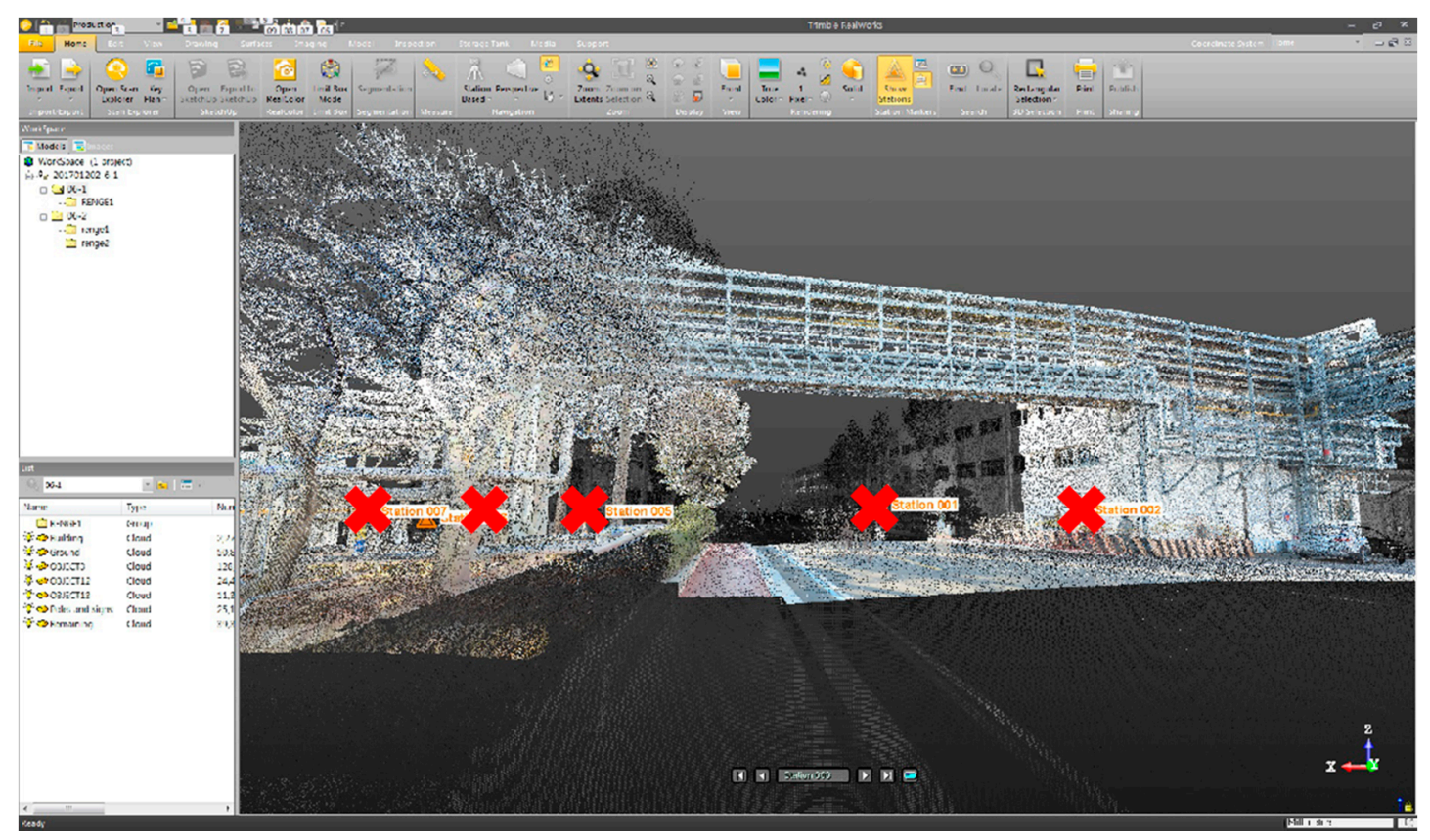

Figure 7. Laser scanning points.

Generating BIM Data for Given Conditions

Point cloud data can be associated with various data formats as shown in Figure 8. The point cloud data acquired through laser scanning accurately reflected the status of the target facilities. 
Although Realworks integrates point cloud data and provides functions to use them in various ways, the data were connected to the CAD and BIM for structural analysis, creating a status drawing, and securing facility management data. In the project, Revit was used as the authoring tool for the BIM data because the information it generates is useful for the structural analysis task. In other words, the structural BIM model for the facilities based on Revit was used as the model for structural analysis. As mentioned Section 2.2, the BIM model should be comparable to laser scanning data. Therefore, the BIM model is not modeled in the same way as the 3D shape of the laser scanning data reflecting the post-transformation state of the facility. However, the BIM model for the pipe rack was constructed based on the exact positional coordinates. Although this method is very simple, it can overcome the limitations of accuracy in automatically modeling the BIM model from laser scanning data. In addition, the manpower required for additional work required to build a BIM model using laser scanning data can be reduced. Most importantly, it provides two quantitative, comparative data (laser scanning data and BIM) to support structural engineer's decision making, which is the subject of assessing the stability of large-scale facilities in the structural safety diagnosis service.

\section{Method of Structural Safety Diagnosis}

Structural engineers can make accurate judgments by comparing and analyzing two pieces of information in a structural safety diagnosis. The first piece of information is laser scanning data that reflects the deformation of large-scale civil infrastructure. The second information is the BIM model which does not reflect the deformation state created by referring to the laser scanning data. The two pieces of information can be integrated in 3D as shown in Figure 9.

Using the integrated 3D model (Figure 9) for conditions prevailing at the given time, the plan, elevation, and cross-sectional information was extracted, and the structural safety diagnosis of large-scale civil infrastructure was then performed. With reference to the integrated 3D model, the structural engineer performs the structural safety diagnosis. As shown in Figure 10, the cross-sectional information of the structural problem can be freely extracted from the 3D model, and the degree of deflection can be grasped by comparing and analyzing the laser scanning data and the BIM model.

Furthermore, it was possible to perform structural safety diagnosis for a specific area using laser scanning and BIM data. Figure 11 shows a visual representation of the deflection analysis of the truss supporting the pipes passing through the pipe rack.

The structural engineer analyzes the deflection of the truss at a specific location by reviewing the section of the 3D model incorporating the laser scanning data and the BIM model. The degree of deflection is analyzed by directly comparing the laser scanning data, which reflects the deformation of the facility, and the BIM model before the deformation, through the extracted section. Through this analysis, structural engineer perform structural safety diagnosis. The contents of analysis included the magnitude of deflection, its span, and deflection-to-span ratio according to the measurements.

Figure 12 shows the structural safety diagnosis results for the deflection of the truss. The values of points A, B, and C shown in Figure 12 indicate the level difference ( $\mathrm{z}$ value difference) between laser scanning data and BIM model at each position. The magnitude of deflection and deflection-to-span ratio were calculated by the following Equations (1) and (2). Based on these results, the structural engineer evaluates the structural safety of large-scale civil infrastructure. Based on these results, a follow-up repair and reinforcement plan will be established.

$$
\text { Deflection }=\mathrm{B}-(\mathrm{A}+\mathrm{C}) / 2
$$

Deflection-to-span ratio $=$ Deflection $/$ Span 

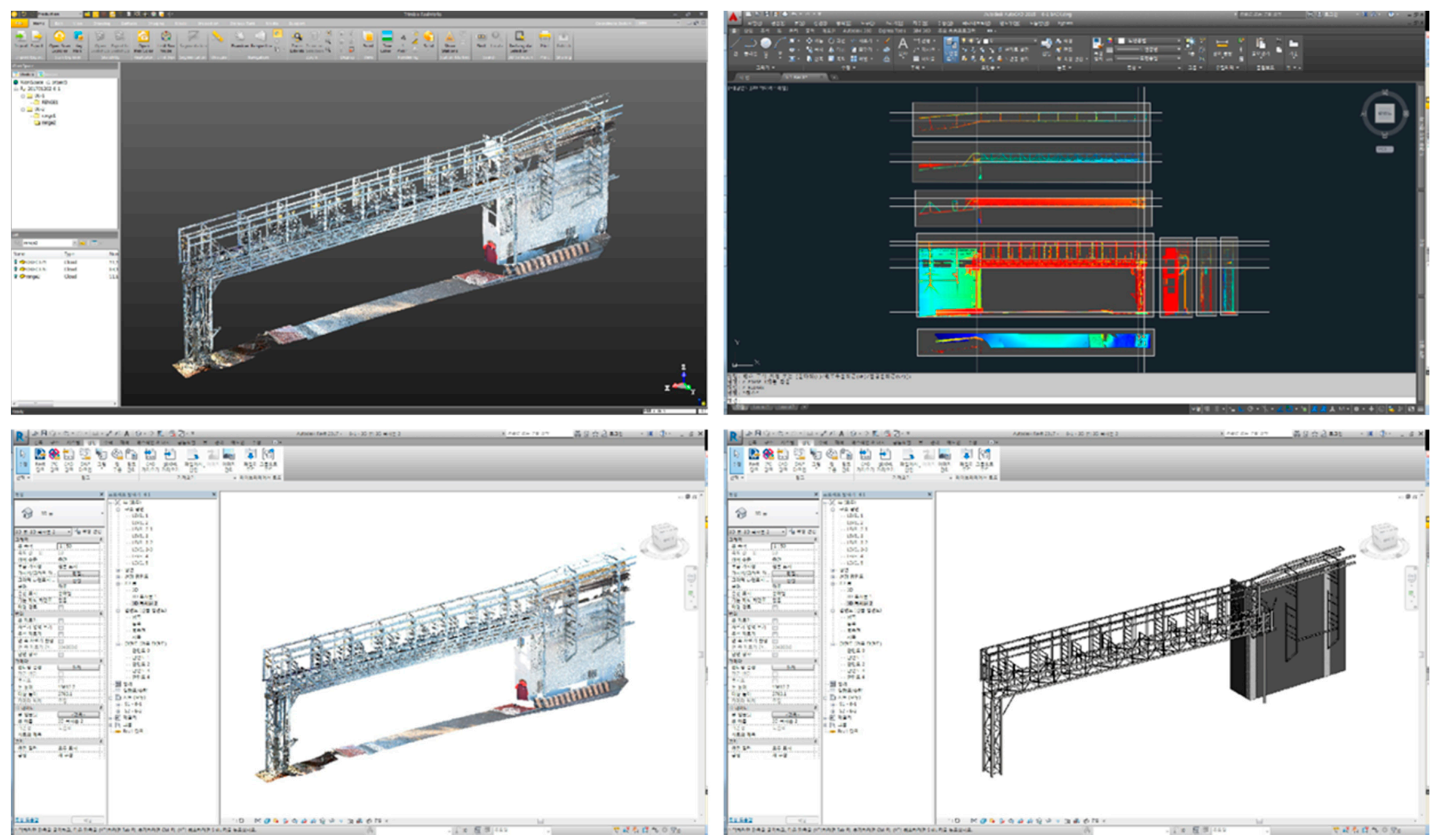

Figure 8. Point cloud data (upper left), integration of point cloud data and CAD (upper right), integration of point cloud data and BIM (lower left), and BIM model (lower right). 


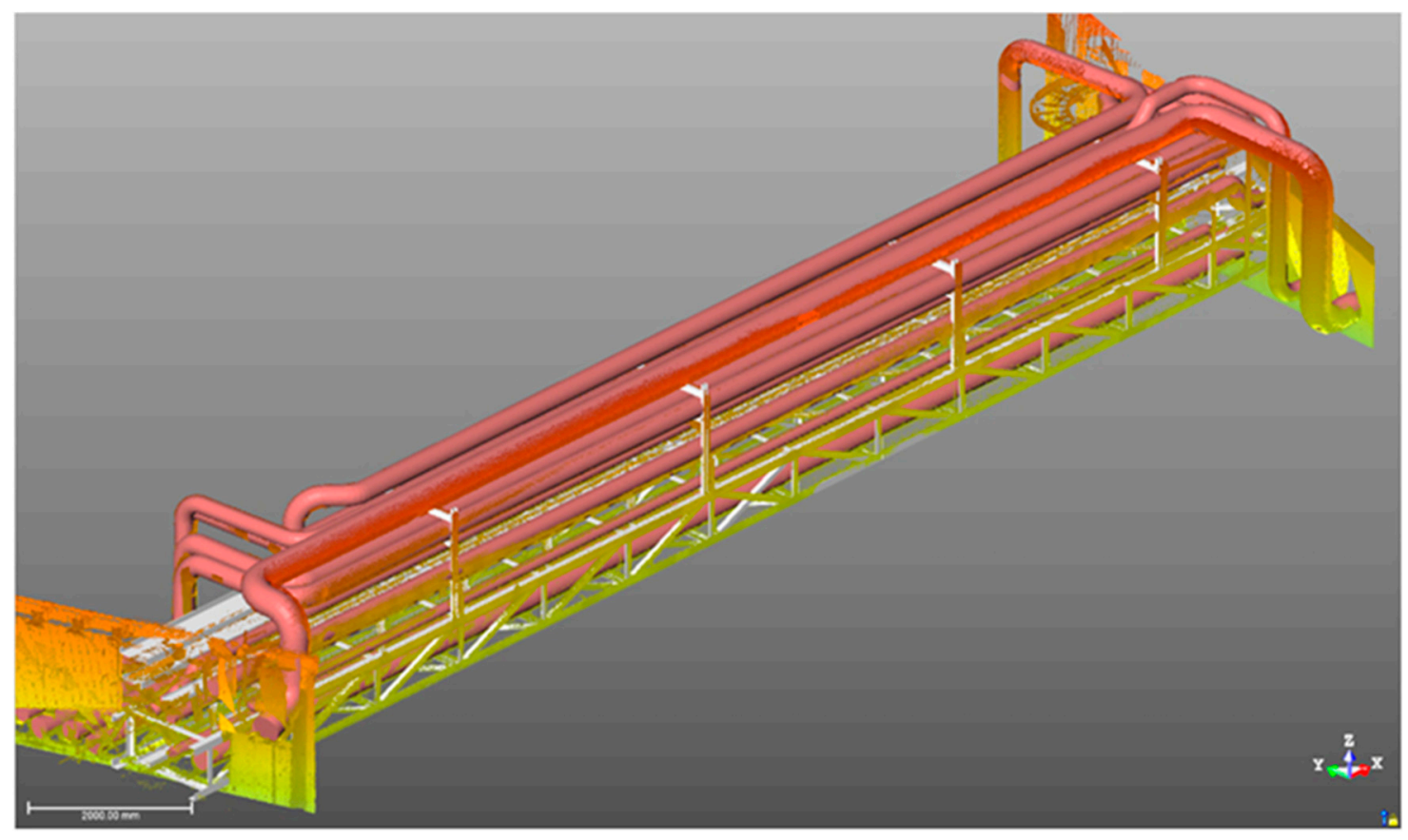

Figure 9. Integration of point cloud data and BIM.
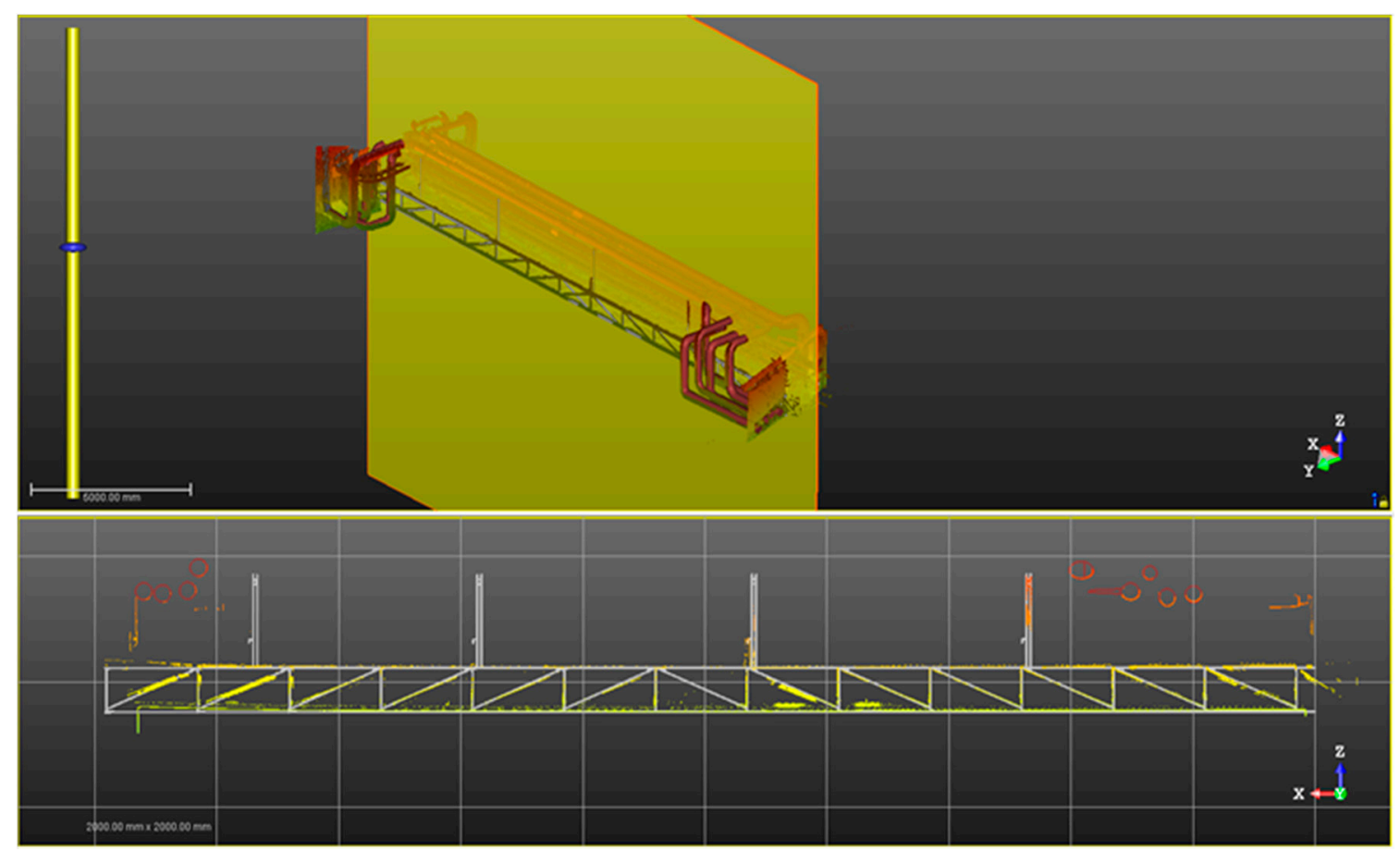

Figure 10. Cross-sectional information extraction of large-scale civil infrastructure. 


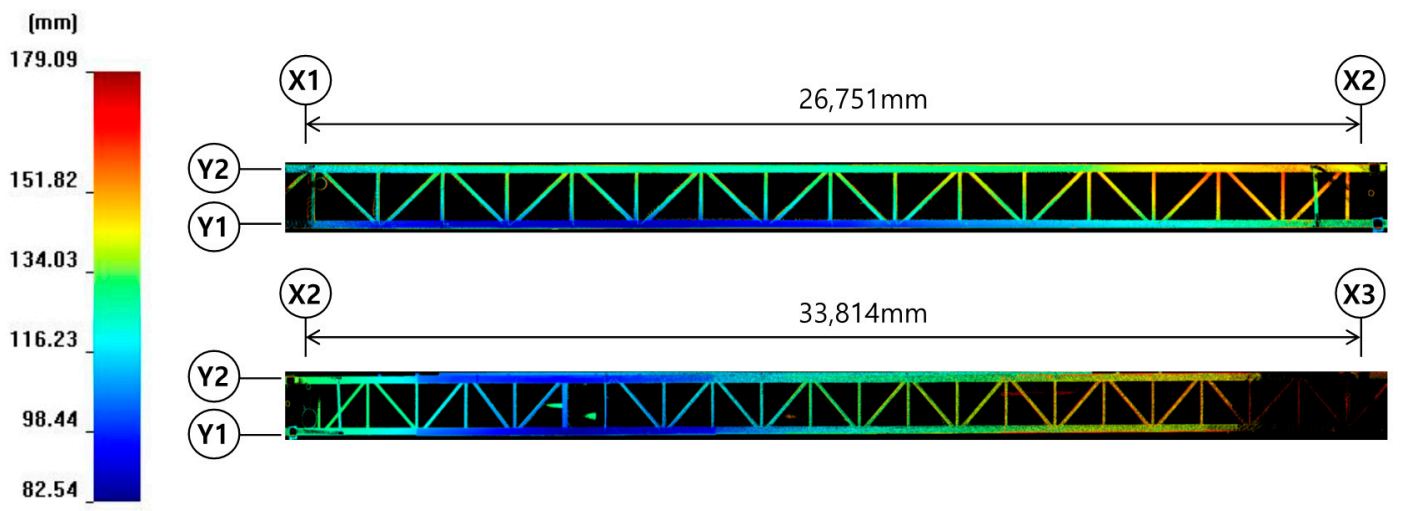

Figure 11. Visual representation of the deflection analysis of truss.

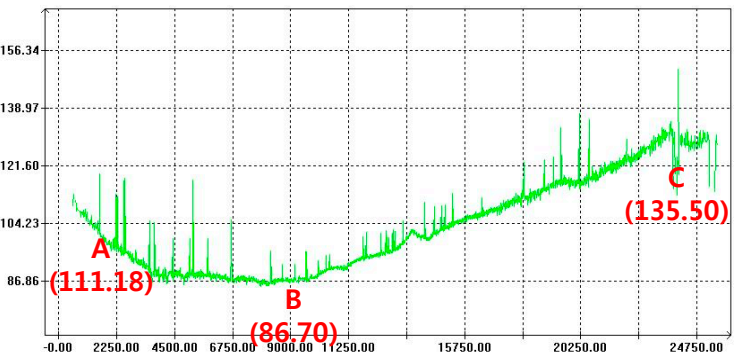

(a) $\mathrm{X} 1 \sim \mathrm{X} 2 / \mathrm{Y} 1$

deflection : $-36.64 \mathrm{~mm}$

span : $26,751 \mathrm{~mm}$

deflection-to-span ratio : $1 / 730$

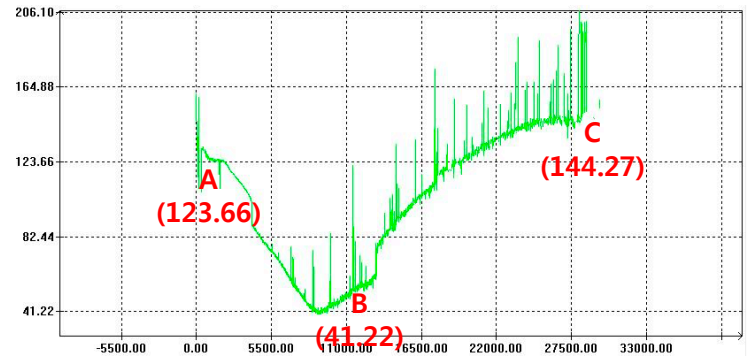

(c) $\mathrm{X} 2 \sim \mathrm{X} 3 / \mathrm{Y} 1$

deflection : $-92.7 \mathrm{~mm}$

span : $33,814 \mathrm{~mm}$

deflection-to-span ratio : $1 / 368$

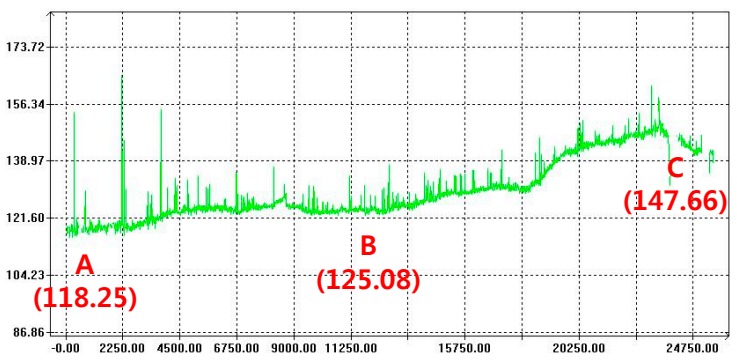

(b) $\mathrm{X} 1 \sim \mathrm{X} 2 / \mathrm{Y} 2$

deflection : $-7.88 \mathrm{~mm}$

span : $26,751 \mathrm{~mm}$

deflection-to-span ratio : below $1 / 1000$

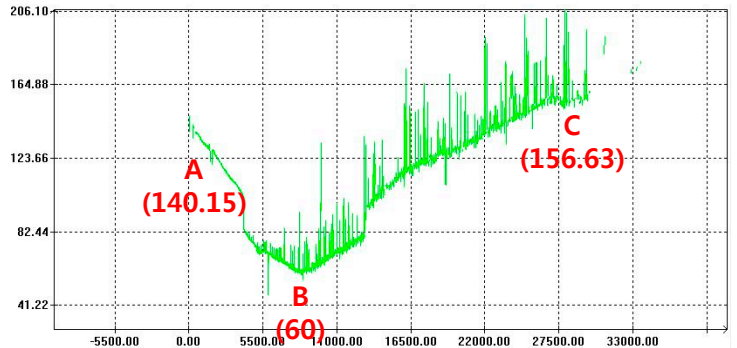

(d) $\mathrm{X} 2 \sim \mathrm{X} 3 / \mathrm{Y} 2$

deflection : $-88.4 \mathrm{~mm}$

span : $33,814 \mathrm{~mm}$

deflection-to-span ratio : $1 / 382$

Figure 12. Structural safety diagnosis results for the deflection of the truss: (a) Location: $X 1 \sim X 2 / Y 1$, (b) Location: X1 X2/Y2, (c) Location: X2 X3/Y1, and (d) Location: X2 X3/Y2.

Tables 3 and 4 show the results of the investigation of the deformation (e.g., degree of tilting) of the column supporting the pipe rack. The structural engineer performs a structural safety diagnosis of the main columns by analyzing sections on the planes extracted from the 3D model incorporating the laser scanning data and the BIM model. The degree of deflection is analyzed by directly comparing the laser scanning data, which reflects the deformation, and the BIM model before the deformation, through the extracted section. The contents of analysis included the direction of displacement, angle of displacement, degree of displacement, displacement ratio according to the measurements. 
Table 3. Structural safety diagnosis of the tilt of the column through plan view.

\begin{tabular}{|c|c|c|c|c|c|}
\hline $\begin{array}{c}\text { Location of } \\
\text { Measurement }\end{array}$ & $\begin{array}{l}\text { Column } \\
\text { Height }\end{array}$ & $\begin{array}{c}\text { Direction of } \\
\text { Displacement }\end{array}$ & $\begin{array}{c}\text { Angle of } \\
\text { Displacement }\end{array}$ & $\begin{array}{c}\text { Degree of } \\
\text { Displacement }\end{array}$ & $\begin{array}{c}\text { Displacement } \\
\text { Ratio }\end{array}$ \\
\hline $\mathrm{X} 1 / \mathrm{Y} 2$ & 7700 & (12) & 0.09 & 12 & Below 1/1000 \\
\hline $\mathrm{X} 1-1 / \mathrm{Y} 1$ & 7700 & (11) & 0.18 & 24 & $1 / 320$ \\
\hline $\mathrm{X} 2 / \mathrm{Y} 2$ & 6300 & (12) & 0.86 & 95 & $1 / 66$ \\
\hline $\mathrm{X} 2-1 / \mathrm{Y} 1$ & 6300 & (11) & 0.78 & 86 & $1 / 73$ \\
\hline $\mathrm{X} 3 / \mathrm{Y} 2$ & 5855 & $\underbrace{(2)}_{i 2}$ & 1.01 & 103 & $1 / 57$ \\
\hline X3-1/Y1 & 5855 & $=$ & 0.61 & 63 & $1 / 93$ \\
\hline
\end{tabular}

Facility Management Using Laser Scanning Data and a BIM Model

The case study of this study focused on the way to investigate the safety status of the large-scale civil infrastructure by comparing the laser scanning data with the BIM model. The advantage of the structural safety diagnosis using the laser scanning data and the BIM model proposed in this study is that it provides quantitative information necessary for long-term operation and maintenance of the large-scale civil infrastructure. This information can be used as basic data for the maintenance and reinforcement planning of large-scale civil infrastructure, and can also be directly used for extracting the drawings for the status of the facilities as shown in Figure 13. Various stakeholders can take advantage of drawings that reflect accurate state of large-scale civil infrastructure. This information can shorten the duration of operational and maintenance services and reduce the workforce. 
Table 4. Structural safety diagnosis of the tilt of the column through section view.

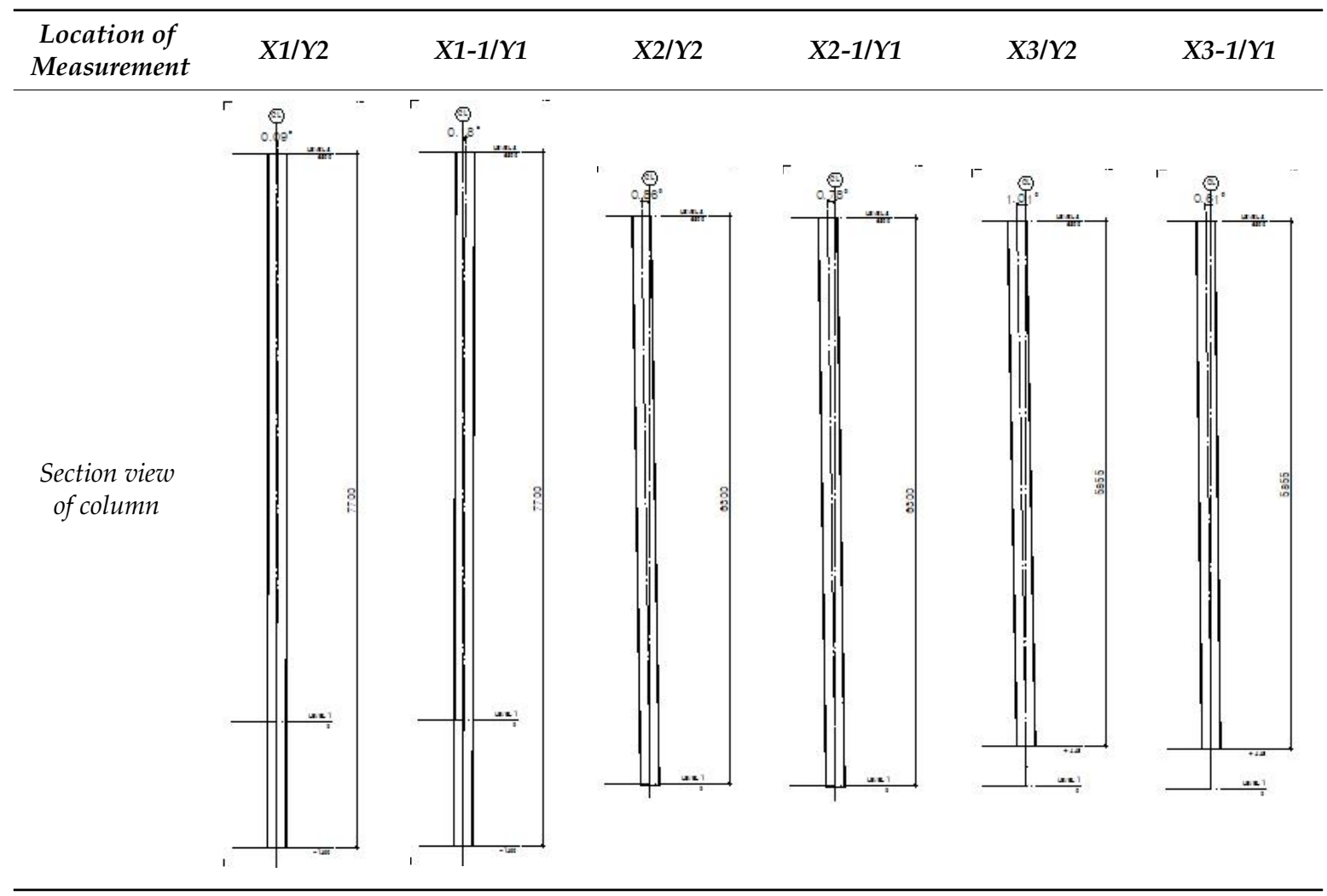




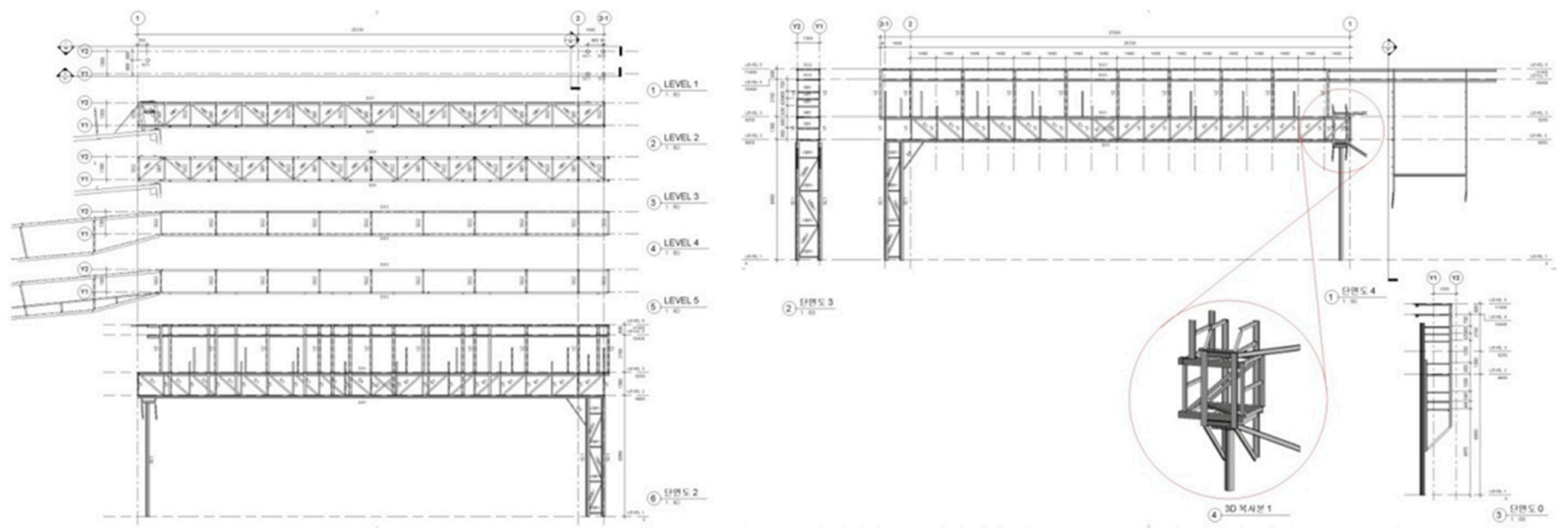

Figure 13. Extracted drawing of facility status. 


\section{Discussion}

Dongyang Structural Engineers Group introduced laser scanning to improve the structural safety diagnosis service of the facility. The purpose of introducing these latest technologies is to improve service quality, reduce input costs, shorten the service period, and secure worker safety. As a result of the interview with the structural engineer who manages the case project, it was confirmed that the manpower input is reduced as shown in Figure 14.

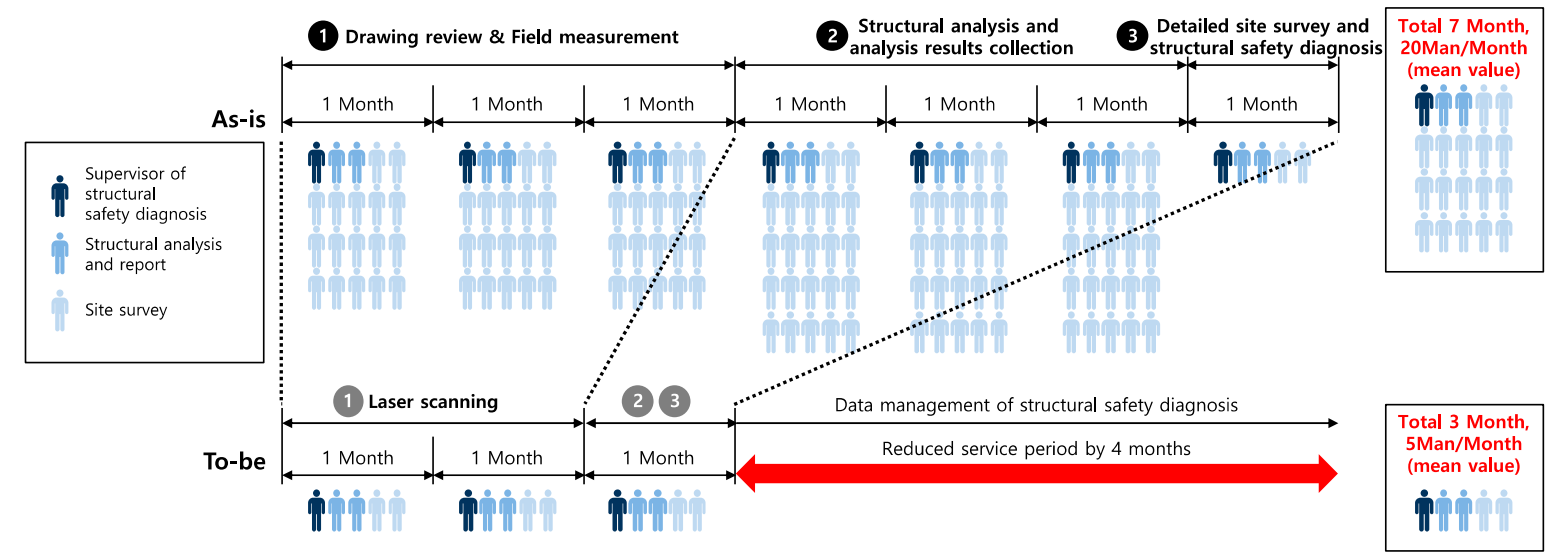

Figure 14. Personnel input comparison (as-is vs. to-be).

In the conventional method, 20 manpower is invested for three months in the drawing review and field measurement of large facilities. Next, 25 manpower is injected into the structure analysis and the collection of analysis results over three months. Finally, five personnel are invested in the detailed field survey and structural safety diagnosis for one month. However, with the introduction of laser scanning, only five people were added to the initial data collection for two months. In addition, only five manpower was put into the structure analysis, collection of analysis results, detailed field survey and structural safety diagnosis work for only one month.

In the service period of the structural safety diagnosis, it saved four months. In terms of personnel savings, interviews revealed that 20 people would have to be put in for an average of seven months (140 man-month) when performing structural safety diagnosis in the existing way. However, when laser scanning and BIM were used, it was found that five manpower was actually invested (15 man-month) for three months on average. In terms of manpower saving, 125 man-month was saved. Existing practice reported that the laser scanning of large bridges took only five days [54]. On the other hand, this study considered not only the time required for laser scanning of a large-scale pipe rack, but also the manpower and duration required for a structural safety diagnosis. In terms of cost efficiency, the laser scanning technology proved to be $50 \%$ cheaper compared with traditional surveying methods and by reducing the need to work through the night savings were made on staff overtime [4]. This research analyzed the cost effectiveness of the structural safety diagnosis method using laser scanning and BIM. The research findings can provide a quantitative basis for the introduction of laser scanning and BIM technology in the structural safety diagnosis of aging large-scale civil infrastructures.

However, the limitations of this study have not yet been analyzed economically by considering the investment cost (e.g., hardware, software, training, etc.) of laser scanning and BIM technology and the cost saving effect of technology introduction. Structural engineering companies in the case project collect information (e.g., man, project period, etc.) to calculate cost effectiveness by applying laser scanning to various areas, as well as structural safety diagnosis. If such information is accumulated, the economic feasibility of the proposed method can be analyzed from a long-term perspective. In addition, we could not analyze the effect of laser scanning on safety improvement of workers. Therefore, it is necessary to analyze the effects of laser scanning and BIM technology (e.g., safety of workers) in a future study. 


\section{Conclusions}

This paper reported a case study to improve the structural safety diagnosis of large-scale civil infrastructure using laser scanning and BIM technologies. From a sustainability perspective, this paper provides a technological approach to laser scanning for aging large-scale civil infrastructures. In addition, we have presented a method to access the displacement of the large-scale civil infrastructure by comparing the data generated from laser scanning and BIM. In this way, we can diagnosis the precise structural safety condition of the aging large-scale civil infrastructure. Based on these accurate diagnoses, we can establish maintenance strategies for large-scale civil infrastructures. Finally, even if it is a very innovative technology in any research field, it is difficult to introduce it if it is not economical. In terms of sustainable construction management, this study presents strategies for recovering investment costs for expensive laser scanning equipment (e.g., laser scanner, SW, training cost, etc.). We confirmed that the proposed structural safety diagnosis method can save service duration and significantly reduce the manpower input compared with the conventional method. The major contributions of this study are as follows:

First, an information generation process for the safety diagnosis of large and aging facilities was proposed. The safety diagnosis must be based on accurate information concerning the status of the civil infrastructure. To this end, a method to generate and utilize information through laser scanning and BIM was proposed. The limitations of the prevalent method of safety diagnosis were also confirmed through the case study and the feasibility of the proposed method was verified.

Second, the economic efficiencies of the prevalent method of safety diagnosis and the proposed safety were analyzed by applying both to the case study. Interviews with officials of the structural engineering offices that had built the facility revealed that the proposed safety diagnosis method was effective in terms of time and personnel input. In other words, when the project was performed using the prevalent safety diagnosis method, 20 personnel were needed for seven months. However, the proposed method required only five people for three months. Finally, proposed method of structural safety diagnosis saved four months. Additionally, in terms of manpower saving, 125 man-month was saved. These results show that the proposed method of safety diagnosis can save cost in terms of time and personnel for AEC/FM companies, which are burdened with the costs of investment.

Third, from the perspective of long-term facility safety management, the feasibility of laser scanning and BIM as methods for managing the status information of facilities was examined. The point cloud data and BIM data for conditions prevailing in the target facility at the given time, generated through laser scanning, can contain a diversity information regarding the facility. Therefore, they are essential data management tools for constructing a safety management system to consistently monitor the safety of facilities.

To improve the capabilities of AEC/FM, which is relatively slow in innovating businesses using the latest technologies, further research is required to analyze ROI (return on investment) of introducing these technologies, e.g., through analyses of the economic efficiency of the maintenance and safety diagnosis that uses laser scanning and BIM, maintenance by securing facility management data, and improvement in the efficiency of safety diagnosis.

Author Contributions: N.H. developed the concept and drafted the manuscript, and S.-H.L. revised the manuscript and supervised the overall work.

Funding: This research was supported by the Basic Science Research Program through the National Research Foundation of Korea (NRF), funded by the Ministry of Education (NRF-2015R1D1A1A01059286).

Acknowledgments: The research was conducted using data for the case study provided by the Dongyang Structural Engineers Group.

Conflicts of Interest: The authors have no conflict of interest to declare. 


\section{References}

1. Noor, M.N.M.; Pitt, M. A critical review on innovation in facilities management service delivery. Facilities 2009, 27, 211-228. [CrossRef]

2. RICS. Royal Institute Chartered Surveyor (RICS). 2010. Available online: http://www.rics.org/my/ knowledge/ (accessed on 13 January 2016).

3. Turkan, Y.; Laflamme, S.; Tan, L. Terrestrial Laser Scanning-Based Bridge Structural Condition Assessment; Iowa State University: Ames, IA, USA, 2016.

4. $\quad 3 D$ Laser Mapping. The Road to Recovery: Using Mobile Laser Scanning for Highways \& Rail. 2016 Copyright@ 1999-2018 3D Laser Mapping. All Rights Reserved I Registered in England \& Wales No. 03851557. Registered Office: Innovation House, Mere Way, Ruddington Fields Business Park, Nottingham. Available online: https:/ / www.3dlasermapping.com/blog-post/lidarforhighwaysandrail/ (accessed on 24 October 2018).

5. Weixing, W.; Weisen, Z.; Lingxiao, H.; Vivian, V.; Zhiwei, W. Applications of terrestrial laser scanning for tunnels: A review. J. Traffic Transp. Eng. 2014, 1, 325-337.

6. Michael, S. Guidelines on Laser Scanning in Plant Design 201, 5th ed.; Fraunhofer Institute for Factory Operation and Automation IFF: Freiburg, Germany, 2018; pp. 1-22. Available online: https:/ / www.iff.fraunhofer.de/ content/dam/iff/en/documents/publications/guidelines-on-laser-scanning-in-plant-design.pdf (accessed on 24 October 2018).

7. Mark, O. How to Use 3D Laser Scanning for Industrial Plant Design: An Engineer's Guide-Part 3: Estimating Scanning Costs. Insights from the Engineers of Matrix Technologies. 2018. Available online: http:/ / matrixti.com/matrix-on-manufacturing/how-to-use-3d-laser-scanning-for-industrial-plantdesign-an-engineers-guide-part-3-estimating-scanning-costs / (accessed on 24 October 2018).

8. KISTEC. Facility Management System. 2018. Available online: https://www.fms.or.kr/ (accessed on 24 October 2018).

9. Kang, T. Study on 3D image scan-based MEP facility management technology. J. KIBIM 2016, 6, 18-26. [CrossRef]

10. KISTEC. Detailed Guidelines on the Safety and Maintenance of Facilities (Safety Inspection and Diagnosis); KISTEC: San Diego, CA, USA, 2018.

11. Nuttens, T.; Stal, C.; Backer, H.D.; Schotte, K.; Bogaert, P.V.; Wulf, A.D. Methodology for the ovalization monitoring of newly built circular train tunnels based on laser scanning: Liefkenshoek Rail Link (Belgium). Autom. Constr. 2004, 43, 1-9. [CrossRef]

12. Ryu, J. Development of an Automation System for Enhancing Infrastructure Safety Inspection Efficiency. Ph.D. Thesis, Incheon National University, Incheon, Korea, 2015.

13. Park, H.S.; Lee, H.M.; Adeli, H. A new approach for health monitoring of structure: Terrestrial laser scanning. J. Comput. Aided Civ. Infrastruct. Eng. 2007, 22, 19-30. [CrossRef]

14. Alsafouri, S.; Ayer, S.K. Review of ICT implementations for facilitating information flow between virtual models and construction project sites. Autom. Constr. 2018, 86, 176-189. [CrossRef]

15. Kim, M.-K.; Cheng, J.C.; Chih-Chen Chang, H.S. A framework for dimensional and surface quality assessment of precast concrete elements using BIM and 3D laser scanning. Autom. Constr. 2015, 49, 225-238. [CrossRef]

16. RIEGL VZ-6000. Technical Specification, RIEGL Inc. 2014. Available online: http://www.riegl.com/nc/ products/terrestrial-scanning/ (accessed on 5 September 2018).

17. Bernardini, F.; Rushmeier, H. The 3D model acquisition pipe line. Comp. Graph. Forum 2002, 21, 149-172. [CrossRef]

18. Son, S.; Park, H.; Lee, K.H. Automated laser scanning system for reverse engineering and inspection. Int. J. Mach. Tool. Manuf. 2002, 42, 889-897. [CrossRef]

19. Kim, C.; Son, H.; Kim, C. Automated construction progress measurement using a 4D building information model and 3D data. Autom. Constr. 2013, 31, 75-82. [CrossRef]

20. Priestnall, G.; Jaafar, J.; Duncan, A. Extracting urban features from LiDAR digital surface models. Comput. Environ. Urban Syst. 2000, 24, 65-78. [CrossRef]

21. Hajian, H.; Becerik-Gerber, B. A research outlook for real-time project information management by integrating advanced field data acquisition systems and building information modeling. Comput. Civ. Eng. 2009, 83-94. [CrossRef] 
22. Teizer, J.; Caldas, C.H.; Haas, C.T. Real-time three-dimensional occupancy grid modeling for the detection and tracking of construction resources. J. Constr. Eng. Manag. 2007, 133, 880-888. [CrossRef]

23. El-Omari, S.; Moselhi, O. Integrating 3D laser scanning and photogrammetry for progress measurement of construction work. Autom. Constr. 2008, 18, 1-9. [CrossRef]

24. FARO. Focus-3D Technical Specification. Available online: http://www.farocom/products/3d-surveying/ laser-scanner-faro-focus-3d/overview / (accessed on 5 September 2018).

25. Olsen, M.J.; Kuester, F.; Chang, B.J.; Hutchinson, T.C. Terrestrial laser scanning-based structural damage assessment. J. Comput. Civ. Eng. 2010, 24, 264-272. [CrossRef]

26. Nahangi, M.; Czerniawski, T.; Haas, C.T. Automated 3D Shape Detection and Outlier Removal in Cluttered Laser Scans of Industrial Assemblies. In Proceedings of the International Conference of Innovation in Construction, Beijing, China, 24-26 May 2015; pp. 1-10.

27. Son, H.; Na, J.; Kim, C. Semantic As-built 3D Modeling of Buildings under Construction from Laser Scan Data Based on Local Convexity without an As-planned Model. In Proceedings of the ISARC International Symposium on Automation and Robotics in Construction, Oulu, Finland, 15-18 June 2015; Volume 32, pp. 1-6. [CrossRef]

28. Gimenez, L.; Hippolyte, J.L.; Robert, S.; Suard, F.; Zreik, K. Review: Reconstruction of 3D building information models from 2D scanned plans. J. Build. Eng. 2015, 2, 24-35. [CrossRef]

29. Bosche, F.; Ahmed, M.; Turkan, Y.; Haas, C.T.; Haas, R. The value of integrating scan-to-BIM and scan-vs-BIM techniques for construction monitoring using laser scanning and BIM: The case of cylindrical MEP components. Autom. Constr. 2015, 49, 201-213. [CrossRef]

30. Reeder, G.D.; Nelson, G.A. Implementation Manual 3D Engineered Models for Highway Construction: The IOWA Experience. 2015. Available online: https://lib.dr.iastate.edu/intrans_reports/130/ (accessed on 1 September 2018).

31. Murphy, K.; van Ginneken, B.; Klein, S.; Staring, M.; de Hoop, B.J.; Viergever, M.A.; Pluim, J.P. Semiautomatic construction of reference standards for evaluation of image registration. Med. Image Anal. 2011, 15, 71-84. [CrossRef] [PubMed]

32. Bhatla, A.; Choe, S.Y.; Fierro, O.; Leite, F. Evaluation of accuracy of as-built 3D modeling from photos taken by handheld digital cameras. Autom. Constr. 2012, 28, 116-127. [CrossRef]

33. Bosche, F. Automated recognition of 3D CAD model objects in laser scans and calculation of as-built dimensions for dimensional compliance control in construction. Adv. Eng. Inform. 2010, 24, 107-118. [CrossRef]

34. Shih, N.J.; Wang, P.H. Using Point Cloud to Inspect the Construction Quality of Wall Finish. In Proceedings of the 22nd eCAADe Conference, Copenhagen, Denmark, 15-18 September 2004; pp. 573-578.

35. Akinci, B.; Boukamp, F.; Gordon, C.; Huber, D.; Lyons, C.; Park, K. A formalism for utilization of sensor systems and integrated project models for active construction quality control. Autom. Constr. 2006, 15, 124-138. [CrossRef]

36. Han, S.; Choe, H.; Kim, S. Automated and efficient method for extraction of tunnel cross-sections using terrestrial laser scanned data. J. Comput. Civ. Eng. 2013, 27, 274-281. [CrossRef]

37. Gordon, S.; Lichti, D. Modeling terrestrial laser scanner data for precise structural deformation measurement. J. Surv. Eng. ASCE 2007, 133, 72-80. [CrossRef]

38. Teza, G.; Galgaro, A.; Moro, F. Contactless recognition of concrete surface damage from laser scanning and curvature computation. NDTE Int. 2009, 42, 240-249. [CrossRef]

39. Tang, P.; Huber, D.; Akinci, B. Characterization of laser scanners and algorithms for detection flatness defects on concrete surfaces. J. Comput. Civ. Eng. 2011, 25, 31-42. [CrossRef]

40. Liu, W.; Chen, S.; Hauser, E. Lidar-based bridge structure defect detection. Exp. Tech. 2011, 35, 27-34. [CrossRef]

41. Golparvar-Fard, M.; Bohn, J.; Teizer, J.; Savarese, S.; Peña-Mora, F. Evaluation of image-based modeling and laser scanning accuracy for emerging automated performance monitoring techniques. Autom. Constr. 2011, 20, 1143-1155. [CrossRef]

42. Brilakis, I.; Lourakis, M.; Sacks, R.; Savarese, S.; Christodoulou, S.; Teizer, J.; Makhmalbaf, A. Toward automated generation of parametric BIMs based on hybrid video and laser scanning data. Adv. Eng. Inform. 2010, 24, 456-465. [CrossRef] 
43. Zeibak-Shini, R.; Sacks, R.; Ma, L.; Filin, S. Towards generation of as-damaged BIM models using laser-scanning and as-built BIM: First estimate of as-damaged locations of reinforced concrete frame members in masonry infill structures. Adv. Eng. Inform. 2016, 30, 312-326. [CrossRef]

44. Akcamete, A.; Akinci, B.; Garrett, J.H. Potential Utilization of Building Information Models for Planning Maintenance Activities. In Proceedings of the International Conference on Computing in Civil and Building Engineering, Nottingham, UK, 3 June-2 July 2010; Tizani, W., Ed.; Nottingham University Press: Nottingham, UK, 2010; pp. 151-157.

45. Arayici, Y.; Onyenobi, T.; Egbu, C. Building information modelling (BIM) for facilities management (FM): The mediacity case study approach. Int. J. Inform. Model. 2012, 1, 55-73. [CrossRef]

46. Barlish, K.; Sullivan, K. How to measure the benefits of BIM-A case study approach. Autom. Constr. 2012, 24, 149-159. [CrossRef]

47. Becerik-Gerber, B.; Jazizadeh, F.; Li, N.; Calis, G. Application areas and data requirements for BIM-enabled facilities management. J. Constr. Eng. Manag. 2012, 138, 431-442. [CrossRef]

48. Volk, R.; Stengel, J.; Schultmann, F. Building information modeling (BIM) for existing buildings-Literature review and future needs. Autom. Constr. 2014, 38, 109-127. [CrossRef]

49. Ani, A.I.C.; Johar, S.; Tawil, N.M.; Razak, M.Z.A.; Hamzah, N. Building Information Modeling (BIM)-based building condition assessment: A survey of water ponding defect on a flat roof. J. Teknol. Sci. Eng. 2015, 9, 25-31.

50. Smith, D.K.; Tardif, M. Building Information Modelling: A Strategic Implementation Guide for Architects, Engineers, Contractors, and Real Estate Asset Management; John Wiley \& Sons: Hoboken, NJ, USA, 2009.

51. Berahim, N.; Jaafar, M.N.; Razali, M.N. A Review on the Principle of Governance in Asset Management to Enhance the Performance of Local Authority in Malaysia. In Proceedings of the Global Conference on Business, Economics and Social Sciences 2013, Kuala Lumpur, Malaysia, 25-26 June 2013; pp. 262-273.

52. Lee, H.J.; Kang, S.Y.; Lee, S.H.; Song, S.H. 3D Laser Scanner for Reverse Engineering. Magazine of KIBIM, 29 September $2015 ; 25-41$.

53. Kim, K.Y.; Chae, J.H. Introduction to Reverse Engineering Process and Practical Examples: BIM Practice 4. Magazine of KIBIM, 29 September 2015; 67-79.

54. Speed, V. How to Laser Scan a Bridge in Five Days. 2015. Available online: http://lidarmag.com/wpcontent/uploads/PDF/LiDARNewsMagazine_Speed-ScanABridgeInFiveDays_Vol5No3.pdf (accessed on 24 October 2018).

(C) 2018 by the authors. Licensee MDPI, Basel, Switzerland. This article is an open access article distributed under the terms and conditions of the Creative Commons Attribution (CC BY) license (http://creativecommons.org/licenses/by/4.0/). 